\title{
Atrial fibrillation and its influence on stroke risk
}

This article was published in the following Dove Press journal:

Research Reports in Clinical Cardiology

9 February 2015

Number of times this article has been viewed

\author{
Domenico Prisco ${ }^{1,2}$ \\ Caterina Cenci' \\ Elena Silvestri, ${ }^{1,2}$ \\ Lucia Ciucciarelli ${ }^{1,2}$ \\ Benedetta Tomberli ${ }^{2}$ \\ Carlo Tamburini ${ }^{2}$ \\ 'Department of Experimental and \\ Clinical Medicine, University of \\ Florence, Florence, Italy; ${ }^{2}$ Patologia \\ Medica Unit, Careggi University \\ Hospital, Florence, Italy
}

Correspondence: Domenico Prisco Department of Experimental and Clinical Medicine, University of Florence, Largo Brambilla 3, 50I34 Florence, Italy Email priscod@aou-careggi.toscana.it

\begin{abstract}
Atrial fibrillation (AF) is the most common cardiac arrhythmia in the clinical setting. $\mathrm{AF}$ increases both the risk and severity of stroke, and is associated with substantial morbidity and mortality. Decisions regarding appropriate stroke prevention in AF patients are crucial and require individual assessment of both thromboembolic and bleeding risk. This review will provide an overview of recommended risk assessment tools and discuss other possible risk factors which could improve risk stratification in AF patients.
\end{abstract}

Keywords: atrial fibrillation, stroke, thromboembolism, risk stratification

\section{Introduction}

Atrial fibrillation (AF) represents a major independent risk factor for stroke, causing a three to five fold increased risk. ${ }^{1}$ Strokes associated with AF are known to be more severe, resulting in greater mortality and morbidity, more disability, longer in-patient stay, and lower rates of discharge to the patient's own home. ${ }^{2}$ It becomes clear how the earliest detection of AF is crucial in patients presenting with ischemic stroke, and, on the other hand, an accurate evaluation of both thromboembolic and bleeding risk is mandatory in AF patients, in order to maximize the benefits of an appropriate antithrombotic therapy and minimize adverse events.

Current guidelines have proposed validated risk stratification schemes and, more recently, many efforts have been made to identify new possible risk factors in order to improve the stratification of thromboembolic risk in AF patients.

\section{Stroke and AF}

Stroke represents the second leading cause of mortality worldwide, split almost evenly between ischemic and non-ischemic, and has a significant impact on the total health care burden. ${ }^{3}$ Its incidence and prevalence are estimated to significantly increase in the near future. This trend seems to be due to an increase in the prevalence of key risk factors for stroke such as advancing age, diabetes mellitus, hypertension, dyslipidemia, and other underlying cardiovascular conditions, in particular AF. ${ }^{4-6}$

AF is a supraventricular tachyarrhythmia characterized by uncoordinated electrical activation of the atria with consequent deterioration of their mechanical function. ${ }^{7}$ It affects over two million individuals in the USA and its prevalence is expected to rise substantially in the next few decades because of the ageing population, improved cardiovascular treatments, and lengthened survival time of individuals with heart disease. ${ }^{8,9}$ AF itself carries an increased risk of ischemic stroke resulting from embolization of 
thrombi that form within the left atrium (LA) of the heart through all the components of Virchow's triad of thrombogenesis 1) "abnormal blood flow" (as evidenced by stasis in LA due to the absence of an effective contraction), "abnormal blood constituents" (related to the activation of clotting and platelets found in AF patients) and, finally, "vessel wall abnormalities" (because AF contributes to the structural damage of heart walls).

It has also been estimated that between $15 \%$ and $30 \%$ of all acute stroke patients have AF at the time of clinical presentation. ${ }^{10}$ Strokes associated with AF are typically more severe, resulting in greater mortality and morbidity, more disability, longer in-patient stay, and a lower rate of discharge to the patient's own home. ${ }^{2}$ Worse outcomes were initially demonstrated in epidemiological studies in North American and European populations (in which mortality in patients with AF was at least 1.7 fold higher than in those without AF) and these findings have been replicated worldwide. ${ }^{11}$ Post-stroke mortality is also significantly increased in AF-related stroke patients compared to patients without AF. ${ }^{12}$ As a consequence, AF causes a significant rise in costs for the health systems, with the majority being due to direct hospital and medical costs. ${ }^{13}$

\section{Common risk factors for stroke}

The Stroke in Atrial Fibrillation Working Group published a systematic review that identified prior stroke/transient ischemic attack (TIA)/thromboembolism, increasing age, hypertension, and diabetes mellitus as the most consistent independent risk factors for stroke in patients with $\mathrm{AF}{ }^{14,15}$ Moreover, leftventricular dysfunction, defined variously in terms of recent congestive heart failure, left-ventricular fractional shortening less than $25 \%$, or an ejection fraction less than $50 \%$, was widely demonstrated to be a significant risk factor for stroke as well as a history of stroke or TIA. ${ }^{16}$ Regarding sex, some studies ${ }^{17-21}$ found being female to be a significant independent risk factor for stroke, while others ${ }^{22-26}$ did not show this association. Of note, current European Society of Cardiology (ESC) guidelines ${ }^{27}$ recommend considering women with AF without any other risk factor for stroke as having a global risk score of 0 , so they should not assume any antithrombotic therapy. However, recently, a study by Chao et $\mathrm{al}^{28}$ questioned this assumption: the authors enrolled 509 males $\left(\mathrm{CHA}_{2} \mathrm{DS}_{2}\right.$-VASc score 0$)$ and 320 females ( $\mathrm{CHA}_{2} \mathrm{DS}_{2}$-VASc score 1$)$ with AF, who were not receiving, according to guidelines, any antithrombotic therapy and matched control subjects without AF and any comorbidity from $\mathrm{CHA}_{2} \mathrm{DS}_{2}$-VASc (mean age 45 years). During the followup, 128 patients $(1.4 \%)$ experienced ischemic stroke but, while the event rate did not differ between groups with and without
AF for male patients ( $1.6 \%$ versus $1.6 \% ; P=0.920)$, AF resulted in a significant risk factor for ischemic stroke among females (hazard ratio, 7.77 ), with event rates of $4.4 \%$ and $0.7 \%$ for female patients with and without AF $(P<0.001)$.

Major risk factors that are associated with AF have been used to develop, over the years, risk prediction models for embolic stroke, in order to better stratify patients who might receive thromboprophylaxis.

\section{Risk stratification models}

Current ESC guidelines recommend stratifying AF patients according to the $\mathrm{CHA}_{2} \mathrm{DS}_{2}-\mathrm{VASc}$ score ${ }^{27}$ because it was demonstrated to perform better than the previous risk stratification schemes for the prediction of thromboembolism. Patients with one or more major risk factors (eg, previous stroke, TIA, or systemic embolism, age $>75$ years), or with two or more clinically relevant non-major risk factors (eg, heart failure or moderate to severe left ventricular (LV) systolic dysfunction, hypertension, diabetes mellitus, female sex, age 65-74 years, vascular disease) should be considered for oral anticoagulation such as vitamin $\mathrm{K}$ antagonist, or novel oral anticoagulants (NOACs); patients without risk factors $\left(\mathrm{CHA}_{2} \mathrm{DS}_{2}\right.$-VASc score $\left.=0\right)$ can be managed with no antithrombotic therapy given the very low thromboembolic risk in such subjects and the anticoagulant drug potential for bleeding; ${ }^{27}$ patients with one clinically relevant non-major risk factor only $\left(\mathrm{CHA}_{2} \mathrm{DS}_{2}-\mathrm{VASc}\right.$ score $\left.=1\right)$ could be managed preferably with oral anticoagulation, although this indication is controversial. In fact, the most recent guidelines by the American Heart Association ${ }^{29}$ that have accepted, for the first time, the use of $\mathrm{CHA}_{2} \mathrm{DS}_{2}$ score as in Europe, state that for patients with a $\mathrm{CHA}_{2} \mathrm{DS}_{2}$-VASc of 1 , no antithrombotic therapy or treatment with an oral anticoagulant or aspirin may be considered. A recent analysis ${ }^{30}$ of AF patients from the AVERROES and ACTIVE ${ }^{31,32}$ trials who were treated with aspirin with or without clopidogrel showed that the risk of patients with $\mathrm{CHA}_{2} \mathrm{DS}_{2}$-VASc $=1$ treated only with aspirin was still low (1.1\% per year), questioning the indication of ESC guidelines for this category of patients and supporting recent American Heart Association/American College of Cardiology guidelines. ${ }^{29}$ In addition, the annual stroke rate of $0.6 \%$ in patients with a $\mathrm{CHA}_{2} \mathrm{DS}_{2}-\mathrm{VASc}=1$ seems too low to justify anticoagulation and it is important to note that patients with a $\mathrm{CHADS}_{2}=0$ and $\mathrm{CHA}_{2} \mathrm{DS}_{2}-\mathrm{VASc}=1$ have largely been excluded from the major trials of NOACs. ${ }^{33}$ Therefore, the choice of treatment for patients with $\mathrm{CHA}_{2} \mathrm{DS}_{2}-\mathrm{VASc}=1$ is still a matter of debate and should be considered on an individual basis, balancing the individual risk factor for 
stroke presented by the patient and the concomitant risk of bleeding.

For this reason, the latest ESC guidelines recommend using the HAS-BLED score (Hypertension, Abnormal renal/ liver function, Stroke, Bleeding history or predisposition, Labile international normalized ratio (INR), Elderly $(>65)$, Drugs/alcohol concomitantly) ${ }^{27}$ for the bleeding risk stratification of AF patients, recommending caution and/or regular review of anticoagulant therapy in patients with a HASBLED score $\geq 3$. The HAS-BLED score has been validated in multiple independent populations: ${ }^{34,35}$ in particular, in one analysis of AF patients receiving anticoagulants, the HASBLED score was a good predictor of major bleeding and a modest predictor of cardiovascular events and death. ${ }^{36}$

\section{How to improve stroke risk stratification}

It is well known that most of the "classic" risk factors for stroke, such as hypertension or increasing age, are also risk factors for bleeding, so the approach to AF patients is often difficult. In fact, despite the availability of predictive tools and treatment guidelines, anticoagulant therapies are under-prescribed: some registries have shown that the rate of oral anticoagulation prescribing in patients with AF with a moderate-to-high risk of stroke ranged from $41 \%$ to $65 \% .^{37,38}$ This under-treatment is essentially due to physicians' fear of anticoagulation-related bleeding. ${ }^{39}$

Recently, many efforts are being made to identify other possible risk factors in order to improve the stratification of thromboembolic risk in AF patients. ${ }^{40}$ Given that inherited thrombophilia is a relevant risk factor for venous thromboembolism, Pengo et $\mathrm{al}^{41}$ evaluated factor V Leiden and G20210A factor II gene mutations in patients with AF complicated by systemic thromboembolism and in age- and sex-matched controls with uncomplicated AF in order to demonstrate whether these two genetic alterations could even play a role in the formation and embolization of atrial thrombi in $\mathrm{AF}$ patients. The authors found a significant association between the occurrence of a previous systemic embolism and the presence of the G20210A mutation in the factor II gene $(P<0.05)$, independently of other clinical risk factors. Genetics could also influence the individual risk of developing AF and ischemic stroke as data from the literature have suggested. ${ }^{42}$ Coming back to thrombophilia, Poli et al demonstrated that, in addition to hypertension and a history of previous ischemic events, hyperhomocysteinemia represents an independent risk factor for ischemic complications during wellconducted oral anticoagulation therapy (odds ratio $=13.1) .{ }^{43}$
Other authors have studied the role of inflammation in increasing thromboembolic risk in AF patients: serum levels of C-reactive protein (CRP) seem to correlate with the risk of thromboembolic stroke ${ }^{44}$ and the same association was found for interleukin-6. ${ }^{45}$ More recently, the diffusion of pacemakers, implantable cardioverter-defibrillators, and other implantable monitors have prompted the researchers to investigate whether daily AF burden has prognostic significance in terms of risk of thromboembolic events. ${ }^{41}$ In a study by Boriani et $\mathrm{al}^{46}$ patients with a dual-chamber pacemaker (Medtronic AT-500) and a history of AF were included and a day-by-day trend of AF burden (= time spent in AF during each day) was available for each patient during a 1 year follow-up. Patients were divided into three groups: i) maximum $\mathrm{AF}$ burden $<5$ minutes per day (AF-free); ii) maximum AF burden $>5$ minutes but $<24$ hours per day (AF-5 min); and iii) AF burden of 24 hours or longer (episodes $>24$ hours) (AF-24 h). Patients were also classified according to $\mathrm{CHADS}_{2}$ and $\mathrm{CHA}_{2} \mathrm{DS}_{2}$-VASc risk scores and the authors demonstrated that the sensitivity of this stratification scheme could be improved if associated with the estimate of AF burden.

In the wake of these findings, more recently, several studies about the association between echocardiographic parameters and stroke risk in AF patients have been published. In particular, the association between LA mechanics, measured by $3 \mathrm{D}$ wall-motion tracking technology, and the most common thromboembolic risk scores ( $\mathrm{CHADS}_{2}, \mathrm{CHA}_{2} \mathrm{DS}_{2}$-VASc) has been assessed. LA longitudinal strain and emptying fraction assessed by $3 \mathrm{D}$ wall-motion tracking technology seems to correlate with both $\mathrm{CHADS}_{2}$ and $\mathrm{CHA}_{2} \mathrm{DS}_{2}$-VASc scores, in particular each $10 \%$ of variation in longitudinal strain corresponds to a 0.7 and 0.8 point change in those risk scores respectively. ${ }^{47}$ In addition, it has been demonstrated ${ }^{48}$ that LA enlargement, measured on transthoracic echocardiography, is related to an increased prevalence of markers of stroke, evaluated by transesophageal echocardiography such as LA appendage (LAA) thrombus, LAA low flow velocities, dense spontaneous echocardiographic contrast, and LA abnormality. LAA morphology, visualized by cardiac computed tomography, seems also to be associated with higher periprocedural thromboembolic risk in patients undergoing AF ablation. ${ }^{49}$

Finally, it was demonstrated that a close relationship among chronic kidney disease, stroke, ${ }^{50}$ and $\mathrm{AF}^{51}$ makes the management of patients with renal insufficiency very challenging. In fact, in order to refine stroke risk stratification in this category of frail patients, the renal (R) ${ }_{2} \mathrm{CHADS}_{2}$ score has been recently validated. This score attributes one point each for the presence of congestive heart failure, 
hypertension, age $\geq 75$ years, and diabetes and two points for prior stroke or TIA, with an additional two points for creatinine clearance $<60 \mathrm{~mL} / \mathrm{min}$ (calculated with the Cockcroft-Gault formula) and has been shown to improve net stroke risk reclassification over the $\mathrm{CHADS}_{2}$ score $(P=0.005)$ and over $\mathrm{CHA}_{2} \mathrm{DS}_{2}$ VASc $(P=0.023)$ in AF patients from the ROCKET-AF and ATRIA trials. ${ }^{52}$

\section{Conclusion}

The incidence and prevalence of AF and its most dangerous complication, stroke, are estimated to increase in the near future carrying, as a consequence, a rise in costs for health systems. Decisions regarding appropriate stroke prevention are crucial and require individual assessment of both stroke and bleeding risk. ${ }^{53}$ The use of risk scores such as $\mathrm{CHA}_{2} \mathrm{DS}_{2}-$ VASc and HAS-BLED can help physicians in the selection of appropriate antithrombotic strategies, but sometimes it is not sufficient. Physicians should evaluate AF patients as a whole, maybe identifying other possible markers of stroke risk which, in addition to clinical data and classical risk factors, could improve the definition of those patients at truly low risk who should not be anticoagulated or those who could benefit from NOACs.

\section{Disclosure}

The authors have no conflicts of interest to disclose.

\section{References}

1. Fuster V, Ryden LE, Asinger RW, et al. ACC/AHA/ESC Guidelines for the Management of Patients with Atrial Fibrillation. A report of the American College of Cardiology/American Heart Association Task Force on Practice Guidelines and the European Society of Cardiology Committee for Practice Guidelines and Policy Conferences. Eur Heart J. 2001;22(20):1852-1923.

2. Lip GY. Can we predict stroke in atrial fibrillation? Clin Cardiol. 2012;35 Suppl 1:21-27.

3. Lozano R, Naghavi M, Foreman K, et al. Global and regional mortality from 235 causes of death for 20 age groups in 1990 and 2010: a systematic analysis for the Global Burden of Disease Study 2010. Lancet. 2012;380(9859):2095-2128.

4. Heidenreich P, Trogdon J, Khavjou O, et al. Forecasting the future of cardiovascular disease in the United States: a policy statement from the American Heart Association. Circulation. 2011;123(8):933-944.

5. Roger V, Go A, Lloyd-Jones D, et al. Heart disease and stroke statistics 2012 update: a report from the American Heart Association. Circulation. 2012;125(1):e2-e220.

6. Wang Y, Bajorek B. Safe use of antithrombotics for stroke prevention in atrial fibrillation: consideration of risk assessment tools to support decision-making. Ther Adv Drug Saf. 2014;5(1):21-37.

7. Hersi A, Wyse DG. Management of atrial fibrillation. Curr Probl Cardiol. 2005;30(4):175-234.

8. Go AS, Hylek EM, Phillips KA, et al. Prevalence of diagnosed atrial fibrillation in adults: national implications for rhythm management and stroke prevention: the AnTicoagulation and Risk Factors in Atrial Fibrillation (ATRIA) study. JAMA. 2001;285(18):2370-2375.
9. Miyasaka Y, Barnes ME, Gersh BJ, et al. Secular trends in incidence of atrial fibrillation in Olmsted County, Minnesota, 1980 to 2000, and implications on the projections for future prevalence. Circulation. 2006;114(2):119-125.

10. Jorgensen HS, Nakayama H, Reith J, et al. Acute stroke with atrial fibrillation. The Copenhagen Stroke Study. Stroke. 1996;27(10): $1765-1769$.

11. Rahman F, Kwan GF, Benjamin EJ. Global epidemiology of atrial fibrillation. Nat Rev Cardiol. 2014;11(11):639-654.

12. Lin HJ, Wolf PA, Kelly-Hayes M, et al. Stroke severity in atrial fibrillation. The Framingham Study. Stroke. 1996;27(10): 1760-1764.

13. Andrew NE, Thrift AG, Cadilhac DA. The prevalence, impact and economic implications of atrial fibrillation in stroke: what progress has been made? Neuroepidemiology. 2013;40(4):227-239.

14. Stroke Risk in Atrial Fibrillation Working Group. Comparison of 12 risk stratification schemes to predict stroke in patients with nonvalvular atrial fibrillation. Stroke. 2008;39(6):1901-1910.

15. Lip GY, Halperin JL. Improving stroke risk stratification in atrial fibrillation patients. AM J Med. 2010;123(6):484-488.

16. Agarwal M, Apostolakis S, Lane DA, Lip GY. The impact of heart failure and left ventricular dysfunction in predicting stroke, thromboembolism, and mortality in atrial fibrillation patients: a systematic review. Clin Ther. 2014;36(9):1135-1144.

17. Hart RG, Pearce LA, Mc Bride R, Rothbart RM, Asinger RW. Factors associated with ischemic stroke during aspirin therapy in atrial fibrillation: analysis of 2012 participants in the SPAFI-III clinical trials. The Stroke Prevention in Atrial Fibrillation (SPAF) Investigators. Stroke. 1999;30(6):1223-1229.

18. Hart RG, Pearce LA, Rothbart RM, et al. Stroke with intermittent atrial fibrillation: incidence and predictors during aspirin therapy. Stroke Prevention in Atrial Fibrillation Investigators. $\mathrm{J} \mathrm{Am} \mathrm{Coll} \mathrm{Cardiol.}$ 2000;35(1):183-187.

19. Wang TJ, Massaro JM, Levy D, et al. A risk score for predicting stroke or death in individuals with new-onset atrial fibrillation in the community: the Framingham Heart Study. JAMA. 2003;290(8):1049-1056.

20. Van Latum JC, Koudstaal PJ, Venables GS, et al. Predictors of major vascular events in patients with a transient ischemic attack or minor ischemic stroke and with non rheumatic atrial fibrillation. European Atrial Fibrillation Trial (EAFT) Study Group. Stroke. 1995;26(5): 801-806.

21. Cabin HS, Clubb KS, Hall C, Perlmutter RA, Feinstein AR. Risk for systemic embolization of atrial fibrillation without mitral stenosis. Am J Cardiol. 1990;65(16):1112-1116.

22. No authors listed. Patients with nonvalvular atrial fibrillation at low risk of stroke during treatment with aspirin: Stroke Prevention in Atrial Fibrillation III Study. The SPAF III Writing Committee for the Stroke Prevention in Atrial Fibrillation Investigators. JAMA. 1998;279(16):1273-1277.

23. Petersen P, Kastrup J, Helweg-Larsen S, Boysen G, Godtfredsen J. Risk factors for thromboembolic complications in chronic atrial fibrillation. The Copenhagen AFASAK study. Arch Int Med. 1990;150(4): 819-821.

24. Nakagami H, Yamamoto K, Ikeda U, et al. Mitral regurgitation reduces the risk of stroke in patients with non rheumatic atrial fibrillation. $\mathrm{Am}$ Heart J. 1998;136(3):528-532.

25. Aronow WS, Gutstein H, Hsieh FY. Risk factors for thromboembolic stroke in elderly patients with chronic atrial fibrillation. Am J Cardiol. 1989;63(5):366-367.

26. Aronow WS, Ahn C, Kronzon I, Gutstein H. Risk factors for new thromboembolic stroke in patients $\leq 62$ years of age with chronic atrial fibrillation. Am J Cardiol. 1998;82(1):119-121.

27. Camm AJ, Lip GY, De Caterina R, et al. 2012 focused update of the ESC guidelines for the management of atrial fibrillation. Eur Heart $J$. 2012;33(21):2719-2747.

28. Chao TF, Liu CJ, Chen SJ, et al. Atrial fibrillation and the risk of ischemic stroke: does it still matter in patients with a CHA2DS2-VASc score of 0 or 1? Stroke. 2012;43(10):2551-2555. 
29. January CT, Wann LS, Alpert JS, et al. 2014 AHA/ACC/HRS guideline for the management of patients with atrial fibrillation: a report of the American College of Cardiology/American Heart Association Task Force on Practice Guidelines and the Heart Rhythm Society. Circulation. Epub April 10, 2014.

30. Coppens M, Eikelboom JW, Hart RG, et al. The CHA2DS2-VASc score identifies those patients with atrial fibrillation and a CHADS2 score of 1 who are unlikely to benefit from oral anticoagulant therapy. Eur Heart J. 2013;34(3):170-176.

31. Connolly SJ, Eikelboom J, Campbell J, et al. Apixaban in Patients with Atrial Fibrillation. N Engl J Med. 2011;364:806-817.

32. The ACTIVE investigators. Effect of Clopidogrel Added to Aspirin in Patients with Atrial Fibrillation. N Engl J Med. 2009;360:2066-2078.

33. Piccini JP, Singer DE. Putting risk prediction in atrial fibrillation into perspective. Eur Heart J. 2012;33(12):1431-1433.

34. Pisters R, Lane DA, Nieuwlaat R, et al. A novel user-friendly score (HAS-BLED) to assess 1-year risk of major bleeding in patients with atrial fibrillation: the Euro Heart Survey. Chest. 2010;138(5):1093-1100.

35. Olesen JB, Lip GY, Hansen PR, et al. Bleeding risk in 'real world' patients with atrial fibrillation: comparison of two established bleeding prediction schemes in a nationwide cohort. $J$ Thromb Haemost. 2011;9(8):1460-1467.

36. Gallego P, Roldán V, Torregrosa JM, et al. Relation of the HAS-BLED bleeding risk score to major bleeding, cardiovascular events, and mortality in anticoagulated patients with atrial fibrillation. Circ Arrhythm Electrophysiol. 2012;5(2):312-318.

37. Waldo AL, Becker RC, Tapson VF, Colgan KJ; NABOR Steering Committee. Hospitalized patients with atrial fibrillation and a high risk ofstroke are not being provided with adequate anticoagulation. $J \mathrm{Am}$ Coll Cardiol. 2005;46(9):1729-1736.

38. Fitch K, Broulette J, Pyenson B, et al. Utilization of Anticoagulation Therapy in Medicare Patients with Nonvalvular Atrial Fibrillation. Am Health Drug Benefits. 2012;5:157-168.

39. Sen S, Dahlberg KW. Physician's fear of anticoagulant therapy in nonvalvular atrial fibrillation. Am J Med Sci. 2014;348(6):513-521.

40. Prisco D, Cenci C, Silvestri E, et al. The risk stratification in atrial fibrillation. Intern Emerg Med. 2012;7 Suppl 3:S233-S240.

41. Pengo V, Filippi B, Biasiolo A, et al. Association of the G20210A mutation in the factor II gene with systemic embolism in nonvalvular atrial fibrillation. Am J Cardiol. 2002;90(5):545-547.
42. Bevan S, Markus HS. Genetic profiles in ischaemic stroke. Curr Atheroscler Rep. 2013;15(8):342.

43. Poli D, Antonucci E, Cecchi E, et al. Culprit factors for the failure of wellconducted warfarin therapy to prevent ischemic events in patients with atrial fibrillation: the role of homocysteine. Stroke. 2005;36(10):2159-2163.

44. Thambidorai SK, Parakh K, Martin DO, et al. Relation of C-reactive protein correlates with risk of thromboembolism in patients with atrial fibrillation. Am J Cardiol. 2004;94(6):805-807.

45. Conway DS, Buggins P, Hughes E, Lip GY. Prognostic significance of raised plasma levels of interleukin- 6 and $\mathrm{C}$-reactive protein in atrial fibrillation. Am Heart J. 2004;148(3):462-466.

46. Boriani G, Botto GL, Padeletti L, et al. Improving stroke risk stratification using the CHADS2 and $\mathrm{CHA}_{2} \mathrm{DS}_{2}$-VASc risk scores in patients with paroxysmal atrial fibrillation by continuous arrhythmia burden monitoring. Stroke. 2011;42(6):1768-1770.

47. Islas F, Olmos C, Vieira C, et al. Thromboembolic risk in atrial fibrillation: association between left atrium mechanics and risk scores. A study based on 3D wall-motion tracking technology. Echocardiography. Epub August 5, 2014.

48. Faustino A, Providência R, Barra S, et al. Which method of left atrium size quantification is the most accurate to recognize thromboembolic risk in patients with non-valvular atrial fibrillation? Cardiovasc Ultrasound. 2014;12:28.

49. Kosiuk J, Nedios S, Kornej J, et al. Impact of left atrial appendage morphology on peri-interventional thromboembolic risk during catheter ablation of atrial fibrillation. Heart Rhythm. 2014;11(9): 1522-1527.

50. Lee M, Saver JL, Chang KH, et al. Low glomerular filtration rate and risk of stroke: meta-analysis. BMJ. 2010;341:c4249.

51. Watanabe H, Watanabe T, Sasaki S, et al. Close bidirectional relationship between chronic kidney disease and atrial fibrillation: the Niigata preventive medicine study. Am Heart J. 2009;158(4):629-636.

52. Piccini JP, Stevens SR, Chang JC, et al. Renal dysfunction as a predictor of stroke and systemic embolism in patients with nonvalvular atrial fibrillation: validation of the R(2)CHADS(2) index in the ROCKET AF (Rivaroxaban Once-daily, oral, direct factor Xa inhibition Compared with vitamin $\mathrm{K}$ antagonism for prevention of stroke and Embolism Trial in Atrial Fibrillation) and ATRIA (AnTicoagulation and Risk factors In Atrial fibrillation) study cohorts. Circulation. 2013;127(2):224-232.

53. Senoo K, Lane D, Lip GY. Stroke and bleeding risk in atrial fibrillation. Korean Circ J. 2014;44(5):281-290.
Research Reports in Clinical Cardiology

\section{Publish your work in this journal}

Research Reports in Clinical Cardiology is an international, peerreviewed, open access journal publishing original research, reports, editorials, reviews and commentaries on all areas of cardiology in the clinic and laboratory. The manuscript management system is completely online and includes a very quick and fair peer-review system.

\section{Dovepress}

Visit http://www.dovepress.com/testimonials.php to read real quotes from published authors. 